Article

\title{
The Influence of Application Protocol of Simplified and Universal Adhesives on the Dentin Bonding Performance
}

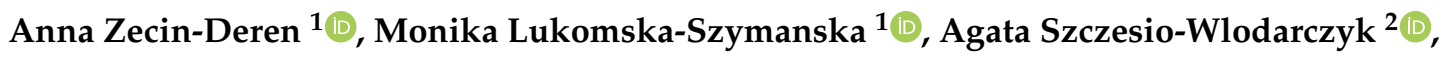 \\ Ireneusz Piwonski ${ }^{3}{ }^{(\mathbb{C}}$, Jerzy Sokolowski ${ }^{1}$ and Barbara Lapinska ${ }^{1, *(\mathbb{C}}$ \\ 1 Department of General Dentistry, Medical University of Lodz, 251 Pomorska St., 92-213 Lodz, Poland; \\ anna.zecin@stud.umed.lodz.pl (A.Z.-D.); monika.lukomska-szymanska@umed.lodz.pl (M.L.-S.); \\ jerzy.sokolowski@umed.lodz.pl (J.S.) \\ 2 University Laboratory of Materials Research, Medical University of Lodz, 251 Pomorska St., \\ 92-213 Lodz, Poland; agata.szczesio@umed.lodz.pl \\ 3 Department of Materials Technology and Chemistry, Faculty of Chemistry, University of Lodz, 163 \\ Pomorska St., 90-236 Lodz, Poland; ireneusz.piwonski@chemia.uni.lodz.pl \\ * Correspondence: barbara.lapinska@umed.lodz.pl; Tel.: +48-42-675-7461
}

Received: 2 December 2019; Accepted: 20 December 2019; Published: 23 December 2019

\begin{abstract}
Contemporary adhesives use etch-and-rinse, self-etch, and multimode adhesive strategies. Simplified and universal adhesives present lower bond strength to dentin than conventional, two-bottle etch-and-rinse adhesives. The purpose of this study was to evaluate bonding performance of simplified and universal adhesives to dentin after modifying their application protocol (multiplying applications and extending application time). Adhesive layer thickness (ALT) and shear bond strength (SBS), as well as the correlation between these parameters was calculated. Two universal (Single Bond Universal and Prime \& Bond One Select) and two self-etch adhesives (Adper Easy One and Xeno V) were tested. Significant differences in ALT were detected between the adhesives, as well as within the same adhesive between study groups. Tested adhesives presented the thinnest adhesive layer when applied 2 times in $20 \mathrm{~s}$. Single Bond Universal obtained the highest SBS results of all adhesives. Most adhesives (except for Prime \& Bond One Select) obtained the highest SBS, when applied two or three times in 40 or $60 \mathrm{~s}$, respectively. No correlation between the ALT and SBS was found. The study showed that increasing the number of applications and extending the application time of self-etch and universal adhesives can be recommended to improve their performance.
\end{abstract}

Keywords: dental adhesives; adhesion; self-etch; universal adhesive; bond strength; dentin; scanning electron microscopy; adhesive layer

\section{Introduction}

The origin of contemporary restorative dentistry dates back to 1955, when Buonocore proposed the acid etching of enamel as a method to increase the adhesion of acrylic restorations to dental tissues [1]. Since then, eight different generations of adhesives, which constitute the intermediate layer between dental fillings and enamel or dentin, have been introduced. The first three generations appeared to provide insufficient bond strength and were withdrawn from clinical use. The fourth and fifth generation is based on the total-etch technique, which consists of phosphoric acid etching of both enamel and dentin in order to create porosities, which increase the adhesion surface of dental tissues.

Micromechanical adhesion is proved to be the prime mechanism in bonding of resin materials to dental tissues [2]. It is achieved in a process, where resin monomers replace inorganic dental component, which leads to the monomers being interlocked in dental porosities, and polymerized [3]. When 
enamel is etched, micro- and macro-porosities are created within hydroxyapatite crystals [4]. Due to the inorganic composition and minimal water content of enamel, hydrophobic adhesive resin uniformly covers its surface [5]. Dentin, being a more organic, water-containing tissue, requires a hydrophilic agent to be entangled within the collagen network, which becomes exposed after etching [6]. In order to eliminate the separate step of etching from bonding procedure, simplified or self-etch (SE) adhesives were introduced. Upon SE adhesive application, the dentin surface is simultaneously demineralized and infiltrated, which theoretically should ensure complete penetration of the adhesive [7]. The acidic monomers, which are responsible for dentin etching, are gradually buffered with increasing depth and finally lose the ability to further etch dentin [8]. Water and other solvents are then evaporated by air-blowing. A polymerized three-dimensional polymer/collagen network is created when the monomer-containing resin is light-cured [7].

SE adhesives require shorter application procedure, are less technique sensitive and present minimized postoperative sensitivity in comparison to etch-and-rinse (ER) adhesives [3]. Further, their performance seems to be less affected by the morphology of the tooth substrate [9]. This is particularly important during fiber post cementation in endodontically treated teeth. The endocanalar zone presents higher density of tubules compared to the crown [10]. According to the studies, the resin-dentin bond strength of ER adhesives decreases with the density of dentinal tubules. Yet, this phenomenon does not apply to SE adhesives and they are recommended to be applied in fiber post cementation $[9,11,12]$. Further, the level of cytotoxicity, presented by SE adhesives is lower than that of the ER ones [13]. Moreover, the SE strategy is valuable in direct pulp capping or endodontic procedures when applied over calcium silicate materials such as Biodentine or mineral trioxide aggregate (MTA) in order to ensure marginal seal and enable placement of composite restoration [14,15]. However, studies show that SE adhesives do not etch enamel sufficiently to achieve a reliable, durable bond [3]. When being applied on dentin, they also present lower bond strength than ER adhesives [16]. To overcome these drawbacks, so called universal or multi-mode (MM) adhesives have been developed. There seems to be no official definition in the literature as to what qualifies as a universal adhesive. However, they can be defined as a single-bottle, no-mix adhesive systems that can be used in ER, SE, or selective-enamel-etch (SEE) mode depending on the specific clinical situation and personal preferences of the operator [17]. In order to enable various etching modes and enhance bond strength, MM adhesives contain functional monomers in their formulation, such as Phenyl-P (N-Phenyl-p-phenylenediamine), 4-MET (4-methacryloxyethyl trimellitic acid) or MDP (methacryloyloxi-decyl-dihydrogen-phosphate). These monomers interact chemically with hydroxyapatite, producing self-assembled nano-layers. The intensity of the process depends on the type of monomer and MDP has proved to be the most efficient one [18]. A nano-layered structure is strongly hydrophobic and helps to protect the formed hybrid layer against hydrolysis [18,19], therefore positively influencing bond strength to dentin. Other constituents of MM adhesives, which may enhance adhesion to tooth structures, are biphenyl dimethacrylate (BPDM), dipentaerythritol pentaacrylate phosphoric acid ester (PENTA) and polyalkenoic acid copolymer [6]. Also, a combination of hydrophilic (hydroxyethul methacrylate, HEMA), hydrophobic (decandiol dimethacrylite, D3MA) and intermediate (bisphenol A-glycidyl methacrylate, bis-GMA) monomers have been employed in the composition of MM adhesives [6]. The hydrophilic ends of these monomers interact with dentin, while the hydrophobic ends interact with methacrylate-based restorative materials or cross-link with other monomers. In case of amphiphilic MDP, its terminal ends are hydrophilic initially but become more hydrophobic when they react chemically with tooth tissues and are polymerized [17]. Also, additives to MM adhesive composition, such as silane, potentially eliminate the silanization step when placing direct or indirect restorations made of glass ceramics, zirconia, metal or resin composites, defining the universal clinical indications of such adhesives [6,20]. In the same time, one should bear in mind that the composition of MM adhesives, aimed at the simplification of the clinical procedure and improvement of bond strength, not only results in their antibacterial activity, e.g., against S. mutans [21], but is also inseparably linked with cytotoxicity, e.g., on gingival fibroblasts [22]. 
According to recent studies, the application of SE and MM adhesives in SEE mode is the most effective protocol to ensure a durable bond to dental tissues [3,23]. When bonding to etched enamel, these adhesives obtain satisfactory results [24]. Yet, when bonding to dentin, alterations of the application procedure were suggested in order to further improve the bond strength of both SE and MM adhesives [25]. These alterations included extending the application time [26] and multiplying the number of consecutive applications (no light-curing in between) [27] or layers (each layer light-cured) [27].

The aim of this study was to determine the effect of multiple applications and extended application time of self-etch and universal adhesives on dentin bond strength and on thickness of adhesive layer as well as the correlation between these parameters. The null hypotheses tested are: (1) There is no effect of multiple applications and extended application time of self-etch and universal adhesives on dentin bond strength. (2) There is no effect of multiple applications and extended application time of self-etch and universal adhesives on thickness of adhesive layer. (3) There is no correlation between adhesive layer thickness and dentin bond strength.

\section{Materials and Methods}

\subsection{Sample Preparation}

Intact human molars $(\mathrm{n}=140)$, stored in $0.5 \%$ chloramine solution to inhibit microbial growth, were used in this study. The teeth were examined for lack of caries and restorations under $10 \times$ magnification optical microscope and used within 2 months of extraction. After being separated from roots, crowns were sectioned mesio-distally in precision micro-cutting machine (Mecatome T210 Prezi, France). Two samples, buccal and lingual, were obtained from each tooth. The enamel of each sample was removed and dentin was exposed and ground (Mecatome T330, Prezi, France) under water lubrication. Silicon carbide papers, 180-grit followed by 600-grit were used to create standardized smear layer on dentin [25]. The dentinal surface was examined for residual enamel under $10 \times$ magnification optical microscope. Institutional Ethical Committee approval was obtained for this study (RNN/435/18/KE).

Dentin samples $(n=280)$ were randomly assigned to 4 groups $(n=70)$ according to the dental adhesive used. The study used two self-etch and two universal dental adhesives (Table 1.).

Table 1. Dental adhesives used in the study.

\begin{tabular}{|c|c|c|c|c|}
\hline Adhesive & Manufacturer & Composition & $\mathrm{pH}$ & Mode of Etching \\
\hline Adper ${ }^{\mathrm{TM}}$ Easy One & 3M ESPE, Germany & $\begin{array}{l}\text { 6-methacryloyloxyhexyl dihydrogen } \\
\text { phosphate (MHP Phosphate Monomer), } \\
\text { Dimethacrylate resins, 2-hydroxyethyl } \\
\text { methacryate (HEMA), Bis-GMA, } \\
\text { Methacrylate functionalized Polyalkenoic } \\
\text { acid (Vitrebond } \\
\text { (silica), Ethanol, Water, Initiators based on } \\
\text { camphorquinone }\end{array}$ & $2.5[28]$ & SE \\
\hline Xeno V & $\begin{array}{l}\text { Dentsply DeTrey } \\
\text { GmbH, Germany }\end{array}$ & $\begin{array}{l}\text { Bifunctional acrylic amides, Acrylamido } \\
\text { alkylsulfonic acid, "inverse" } \\
\text { functionalized phosphoric acid ester, } \\
\text { Acrylic acid, Camphorquinone, } \\
\text { Coinitiator Butylated benzenediol, Water, } \\
\text { tert-Butanol }\end{array}$ & $1.5[28]$ & SE \\
\hline $\begin{array}{l}\text { Single Bond }{ }^{\mathrm{TM}} \\
\text { Universal }\end{array}$ & 3M ESPE, Germany & $\begin{array}{l}\text { MDP Phosphate Monomer, } \\
\text { Dimethacrylate resins, HEMA, } \\
\text { Vitrebond }{ }^{\mathrm{TM}} \text { Copolymer, Nanofiller, } \\
\text { Ethanol, Water, Initiators, Silane }\end{array}$ & $2.7 *$ & $\mathrm{MM}^{1}$ \\
\hline
\end{tabular}


Table 1. Cont.

\begin{tabular}{|c|c|c|c|c|}
\hline Adhesive & Manufacturer & Composition & $\mathrm{pH}$ & Mode of Etching \\
\hline $\begin{array}{l}\text { Prime \& Bond One } \\
\text { Select }\end{array}$ & $\begin{array}{l}\text { Dentsply DeTrey } \\
\text { GmbH, Germany }\end{array}$ & $\begin{array}{c}\text { Bifunctional acryl resin with amide } \\
\text { functions, Acryloylamino alkylsulfonic } \\
\text { acid, "inverse" functionalized phosphoric } \\
\text { acid ester, Camphorquinone, Coinitiator } \\
\text { Butylated benzenediol, Water, } \\
\text { tert-Butanol }\end{array}$ & $1.6[29]$ & $\mathrm{MM}^{1}$ \\
\hline
\end{tabular}

${ }^{1} \mathrm{MM}=$ ER \& SE \& SEE (MM-multimode, ER-etch \& rinse, SE-self-etch, SEE-selective enamel etch). * Information obtained from the manufacturer (safety data sheet).

For each tested adhesive, five study groups $(n=14)$ were designed. The tested adhesives were applied on the dentin surface according to the research model presented in Table 2. The adhesives were light-cured with LED curing lamp (Elipar ${ }^{\mathrm{TM}}$ S10 LED Curing Light, 3M ESPE, Germany). Next, silicone ring with the inner diameter of $3 \mathrm{~mm}$ and height of $4 \mathrm{~mm}$ was placed on the sample surfaces. Flowable composite (Flow-Art, Arkona, Poland) was applied inside the ring and light-cured for $40 \mathrm{~s}$ in 2 equal increments, to ensure complete polymerization. Within each study group, 11 samples were tested for SBS, while 3 samples underwent SEM-EDS analysis of dentin-resin interface.

Table 2. Research model.

\begin{tabular}{cc}
\hline Group & Application Mode \\
\hline $\begin{array}{c}\text { 1A20 } \\
\text { control) }\end{array}$ & $\begin{array}{c}\text { Adhesive was applied according to the manufacturers' instructions: Apply adhesive and rub into the entire dentin } \\
\text { surface with disposable microbrush for } 20 \mathrm{~s} \text {. Gently air-dry the surface for } 5 \mathrm{~s} \text { at a distance of } 10 \mathrm{~cm} \text { to form a } \\
\text { slightly shiny adhesive film. Light-cure for } 20 \mathrm{~s} .\end{array}$ \\
\hline $2 \mathrm{~A} 20$ & Adhesive was applied two times in the abovementioned manner during $20 \mathrm{~s}$ and light-cured for $20 \mathrm{~s}$ afterwards. \\
\hline 3A20 & Adhesive was applied three times in the abovementioned manner during $20 \mathrm{~s}$ and light-cured for $20 \mathrm{~s}$ afterwards. \\
\hline 2A40 & Each of the 2 applications of adhesive lasted $20 \mathrm{~s}$, which made $40 \mathrm{~s}$ in total. The adhesive was light-cured for $20 \mathrm{~s}$. \\
\hline 3A60 & Each of the 3 applications of adhesive lasted $20 \mathrm{~s}$, which made $60 \mathrm{~s}$ in total. The adhesive was light-cured for $20 \mathrm{~s}$. \\
\hline
\end{tabular}

\subsection{SEM and EDS Analysis}

In order to evaluate the interfacial morphology, for each tested adhesive, 3 dentin samples with adhesives applied according to the research model (Table 2) were prepared as described in 2.1. Using 180, 600 and 1000-grit silicon carbide paper under running water, the resin-dentin interface was exposed and polished. The dental etchant, 37\% orthophosphoric acid solution, was applied for $1 \mathrm{~min}$ on the samples in order to demineralize dentin, which was later rinsed with distilled water for $1 \mathrm{~min}$. Next, to remove the organic debris, the specimens were treated by soaking in $5 \% \mathrm{NaOCl}$ for $5 \mathrm{~min}$. The solution was replaced after each minute to prevent it from deactivation. After another distilled water-wash and air-drying, the specimens were dehydrated in ascending ethanol concentration $(50 \%, 70 \%, 90 \%$ and $95 \%$ for $20 \mathrm{~min}$ each and $100 \%$ for $1 \mathrm{~h}$ ), and then transferred to a critical point dryer for $30 \mathrm{~min}$. All specimens were mounted on aluminium stubs, so that the specimens' surface was parallel to the stubs' surface, and sputter-coated with gold layer. The adhesive/dentin interfaces were then examined using a scanning electron microscope (SEM, FEI Nova NanoSEM 450, FEI, Hillsboro, OR, USA) under $1000 \times$ and $2000 \times$ magnification, at $90^{\circ}$ tilt angle. In order to measure adhesive layer thickness (ALT), three different points of adhesive interface: the middle part and both extremities of the interface were evaluated [30]. At each point, four measurements were taken using software that enabled vertical positioning of the adhesive layer and marking parallel measuring lines (perpendicular to the adhesive interface). In total, 12 measurements were taken along the interface of each sample based on SEM images at $2000 \times$ magnification. Further, the dentin-resin interface was analyzed from a chemical aspect, using energy dispersive spectrometry (EDS, EDAX/AMETEK, Materials Analysis Division, Model Octane Super, Mahwah, NJ, USA). 


\subsection{Shear Bond Strength}

For bond strength testing, the dentin samples $(n=220)$ were mounted in round PCV molds, using auto polymerizing acrylic resin, with their prepared surfaces exposed to the environment. As soon as the chemical reaction began, the specimens were placed in cold water to prevent the temperature rise during polymerization of acrylic resin that might negatively affect dental substrate. Next, the samples' surfaces were ground under water lubrication with 600-grit silicon carbide paper to achieve a flat surface and standardized smear layer. The samples were randomly assigned to twenty groups $(n=11)$, depending on the adhesive used and the method of application. The tested adhesives (Table 1) were applied to dentin samples according to the research model presented above (Table 2). Samples were stored in saline for $24 \mathrm{~h}$. Shear bond strength (SBS) was tested with universal testing machine of $20 \mathrm{kN}$ maximum load cell capacity (Zwick-Roell Z005, Zwick-Roell, Germany), running at crosshead speed of $2 \mathrm{~mm} / \mathrm{min}$. Blunt knife-edged chisel was used parallel to dentin-composite adhesive interface with less than $1 \mathrm{~mm}$ gap distance between the crosshead and substrate. The SBS was calculated by corresponding software program and expressed in MPa.

\subsection{Statistical Analysis}

For each tested group, SBS and ALT values were obtained. Minimal and maximal values, mean values, median, standard deviation and coefficient of variation were calculated. Normal distribution was tested with Shapiro-Wilk test. Due to the fact that the results were not normally distributed, nonparametric tests were employed. Multiple comparisons of the SBS of different bonding systems with control were performed with Mann-Whitney's ANOVA. In order to compare each SBS and ALT group with other respective groups, Kruskal-Wallis ANOVA was employed. As a post hoc, Dunnett's test was used, where $p \leq 0.05$ was considered statistically significant. To determine correlation between SBS and ALT, mixed-effects linear regression models with robust standard errors were fitted. All the regression equations were controlled for the modality of application. All the statistical procedures were carried out using STATISTICA 10 (version 10, Publisher: StatSoft, Poland).

\section{Results}

\subsection{SEM and EDS Analysis}

SEM images of dentin-resin interface obtained after treatment of dentin with tested adhesives, according to the research model were presented in Figures 1-4.

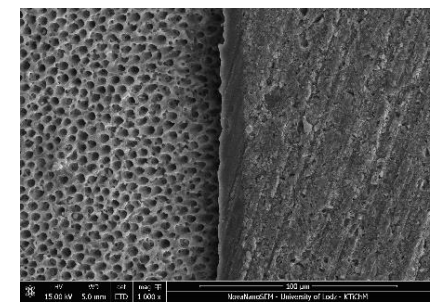

(a)

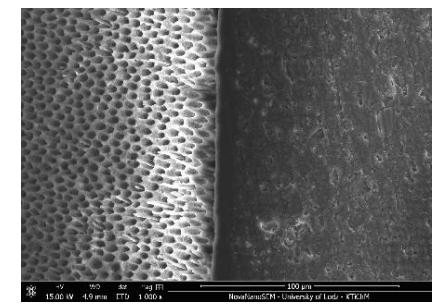

(b)

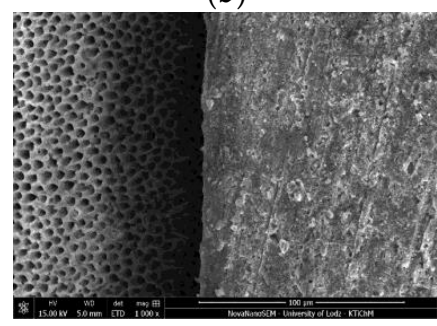

(d)

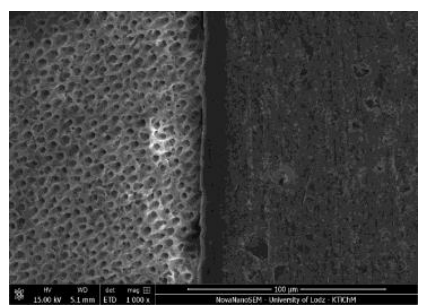

(c)

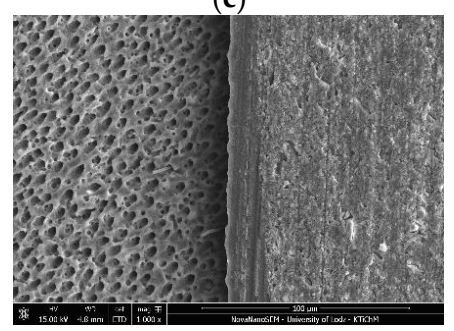

(e)

Figure 1. SEM micrographs of dentin specimens treated with Adper Easy One: (a) 1A20 (control); (b) 2A20; (c) 3A20; (d) 2A40; (e) 3A60; mag. $1000 \mathrm{x}$. 


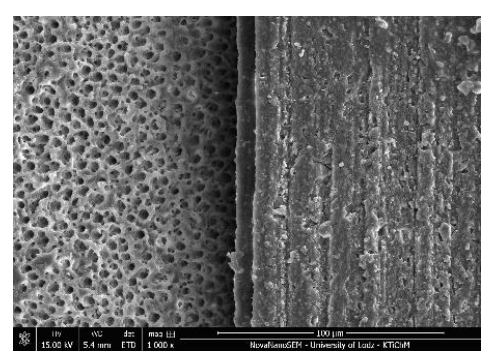

(a)

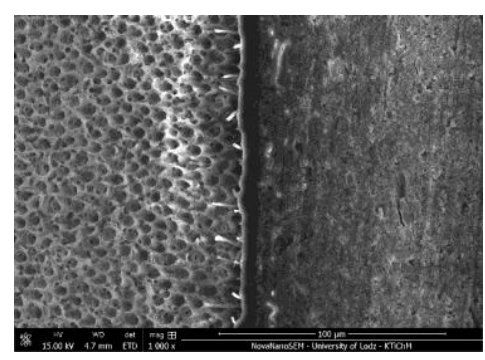

(b)

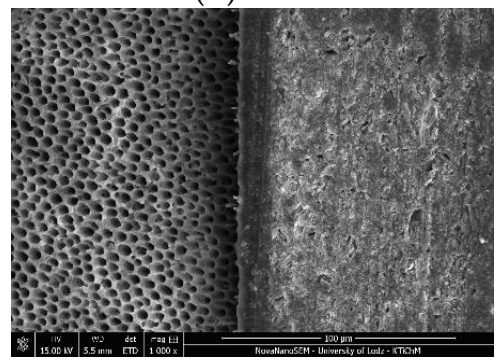

(d)

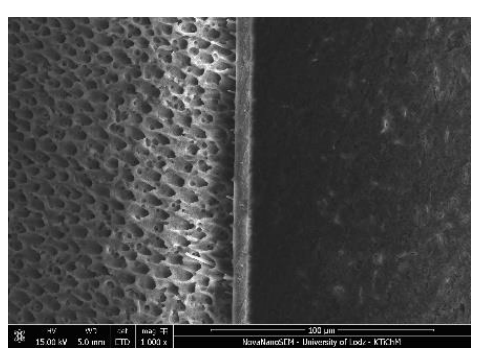

(c)

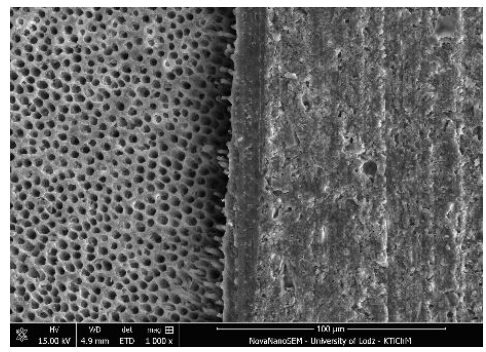

(e)

Figure 2. SEM micrographs of dentin specimens treated with Xeno V: (a) 1A20 (control); (b) 2A20; (c) 3A20; (d) 2A40; (e) 3A60; mag. $1000 \mathrm{x}$.

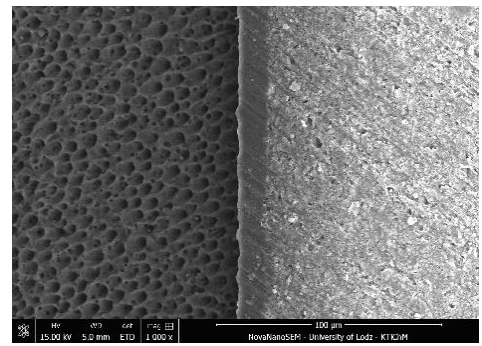

(a)

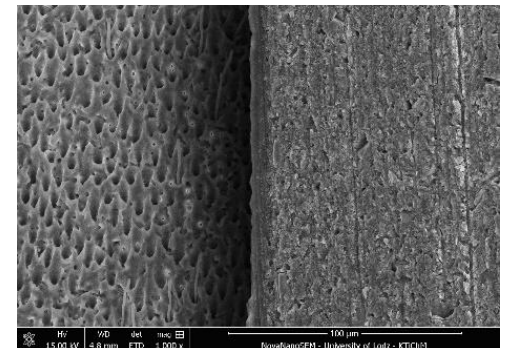

(b)

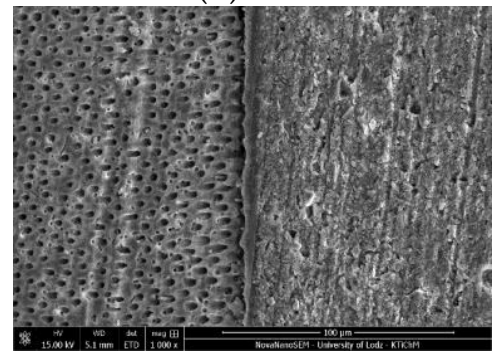

(d)

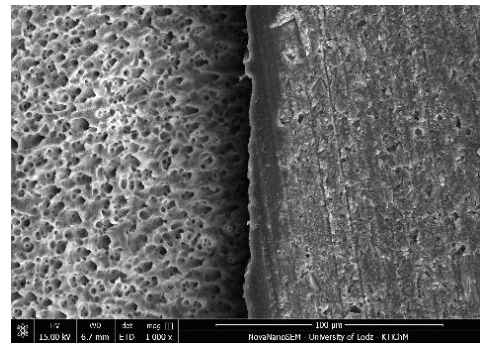

(c)

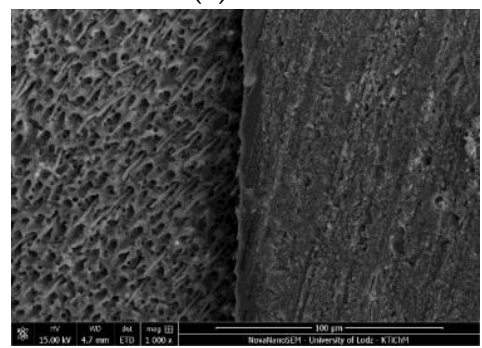

(e)

Figure 3. SEM micrographs of dentin specimens treated with Single Bond Universal: (a) 1A20 (control); (b) 2A20; (c) 3A20; (d) 2A40; (e) 3A60; mag. $1000 \mathrm{x}$. 


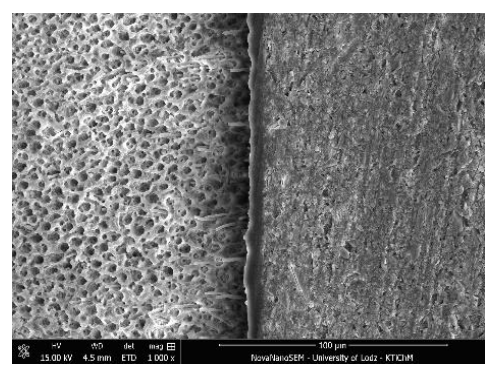

(a)

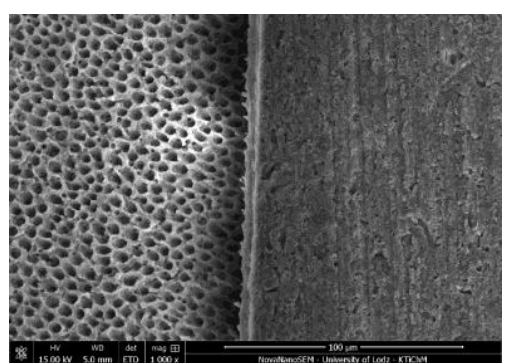

(b)

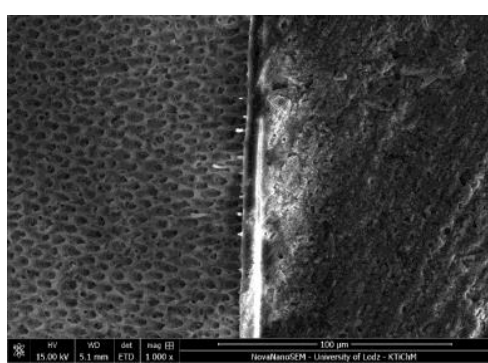

(c)

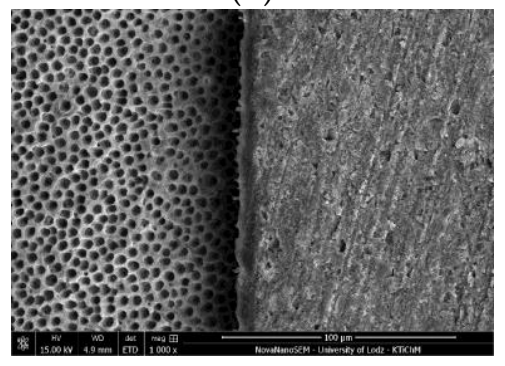

(d)

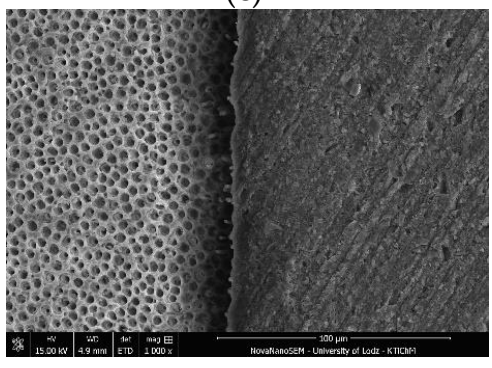

(e)

Figure 4. SEM micrographs of dentin specimens treated with Prime\&Bond One Select: (a) 1A20 (control); (b) 2A20; (c) 3A20; (d) 2A40; (e) 3A60; mag. $1000 \mathrm{x}$.

The mean values of ALT $(\mu \mathrm{m})$ obtained for the tested adhesives were presented in Table 3. For tested adhesives, except for Xeno V, double application in $20 \mathrm{~s}$ resulted in the thinnest adhesive layer among all study groups. The thinnest adhesive layer was obtained for Prime\&Bond One Select (6.31 \pm 0.91$)$. Also, there was no statistically significant difference in adhesive layer thickness between groups within Prime \& Bond One Select. Single Bond Universal, on the other hand, showed the thinnest adhesive layer in 2A20 group and it was significantly lower value than in the control group or in 3A20 group. Adper Easy One reached the lowest mean value in 2A20 group, which was significantly lower than in 3A60 group. The thickest adhesive layer presented Xeno V applied three times in $60 \mathrm{~s}$ $(14.15 \pm 0.67)$ and it was significantly higher, almost double, when compared to the control group.

Table 3. Adhesive layer thickness $(\mu \mathrm{m})$ (mean values \pm standard deviation) of the tested adhesives.

\begin{tabular}{cccccc}
\hline \multirow{2}{*}{ Adhesive } & \multicolumn{4}{c}{ Method of Application } \\
\cline { 2 - 6 } & 1A20 (Control Group) & 2A20 & 3A20 & 2A40 & 3A60 \\
\hline Adper Easy One & $13.31 \pm 0.43^{\mathrm{a}}$ & $9.85 \pm 0.62 \mathrm{a}^{\mathrm{a}, \mathrm{b}}$ & $11.59 \pm 0.75$ & $11.32 \pm 3.20$ & $13.90 \pm 0.51 \mathrm{a}^{\mathrm{a}}$ \\
Xeno V & $7.40 \pm 0.82 \mathrm{a}^{\mathrm{a}, \mathrm{b}}$ & $8.03 \pm 1.09$ & $6.08 \pm 0.21 \mathrm{bc}^{\mathrm{a}}$ & $13.13 \pm 0.08 \mathrm{~b}$ & $14.15 \pm 0.67 \mathrm{ac}^{\mathrm{b}}$ \\
Single Bond Universal & $11.86 \pm 1.69 \mathrm{a}^{\mathrm{b}}$ & $6.43 \pm 0.88 \mathrm{ab}^{\mathrm{a}}$ & $13.25 \pm 0.88 \mathrm{~b}^{\mathrm{a}, \mathrm{b}}$ & $12.48 \pm 12.80$ & $9.32 \pm 0.36$ \\
Prime \& Bond One Select & $7.89 \pm 1.09$ & $6.31 \pm 0.91^{\mathrm{b}}$ & $6.39 \pm 0.65^{\mathrm{b}}$ & $6.86 \pm 0.76$ & $6.38 \pm 0.91^{\mathrm{a}, \mathrm{b}}$ \\
\hline
\end{tabular}

Within tested adhesives, means followed by the same lowercase letters in row and superscript letters in column indicate significant statistical differences.

The results of EDS analyses of the resin-dentin interface (Figures 5-8) confirmed that the concentrations of different elements corresponded with specific layers of that interface. In dentin, mainly calcium and phosphorus were detected. The adhesive layer contained carbon, which is the main element present in resin polymer. Silicon was detected in adhesive layers of Adper Easy One and Single Bond Universal, which can be attributed to the presence of nanofiller in the composition of these adhesives. All tested specimens showed increased content of silicon and aluminum, derived from inorganic filler, in composite material. 


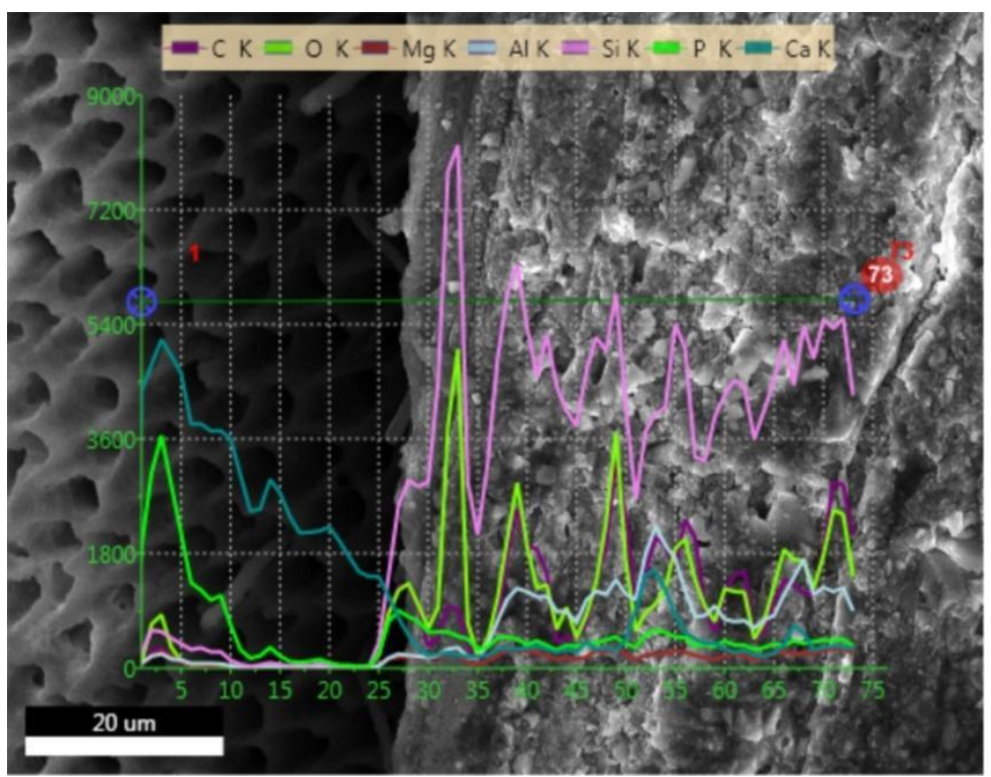

Figure 5. EDS line scan signals of individual elements present at dentin-resin interface obtained for Adper Easy One applied twice in $40 \mathrm{~s}$ (group 2A40).

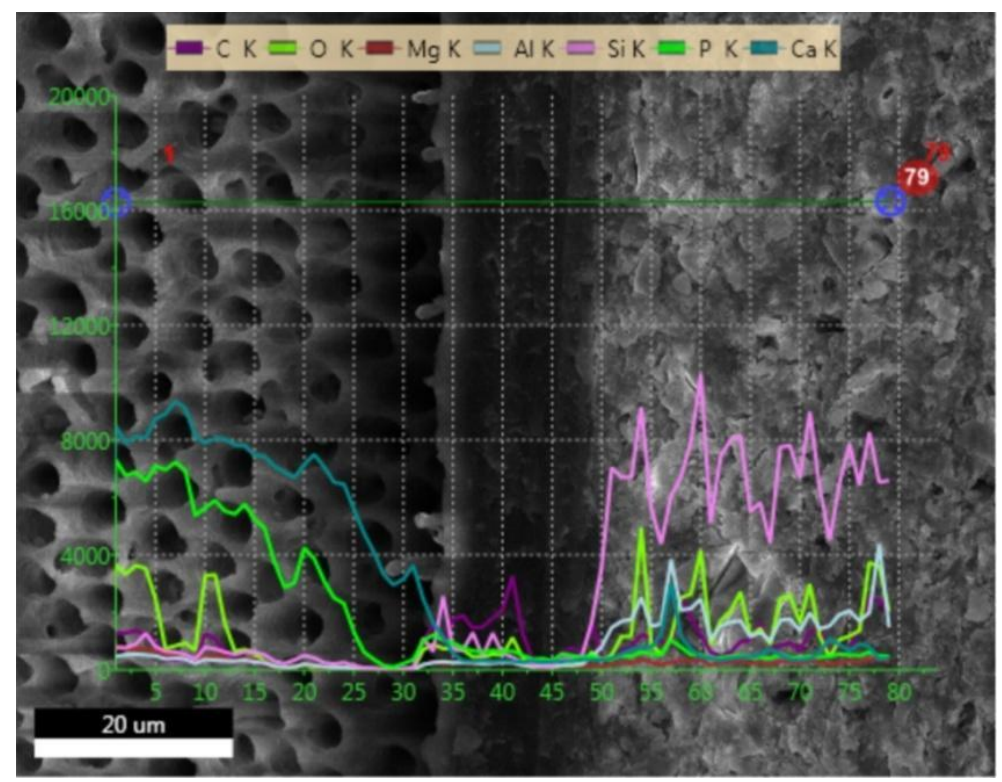

Figure 6. EDS line scan signals of individual elements present at dentin-resin interface obtained for Xeno $\mathrm{V}$ applied twice in $40 \mathrm{~s}$ (group 2A40). 


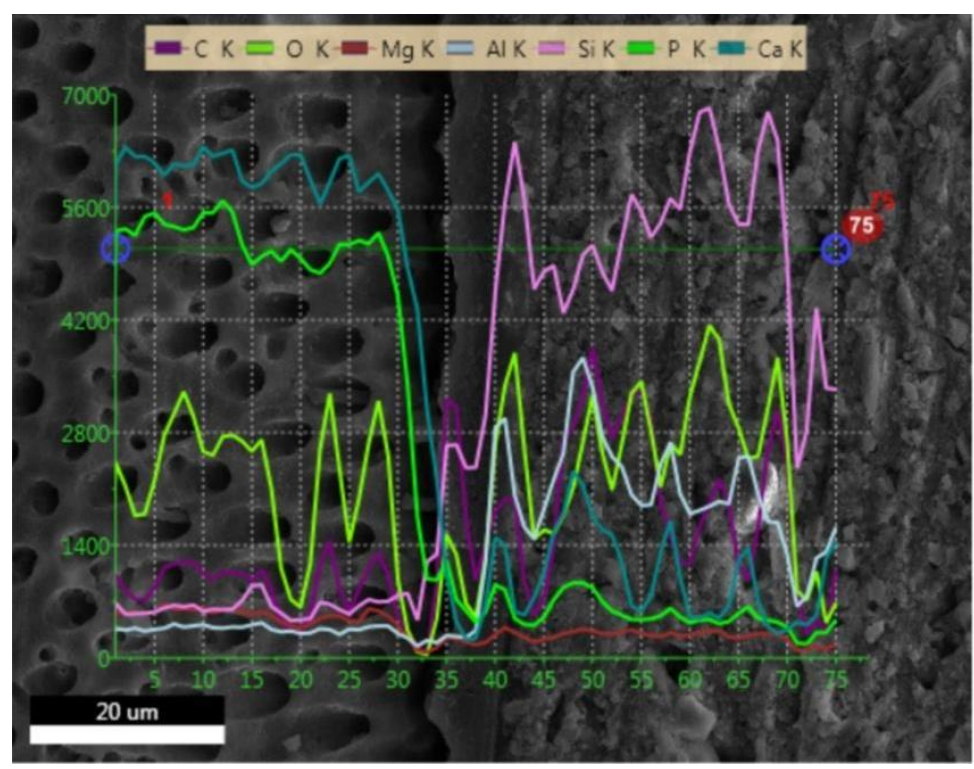

Figure 7. EDS line scan signals of individual elements present at dentin-resin interface obtained for Single Bond Universal applied twice in $40 \mathrm{~s}$ (group 2A40).

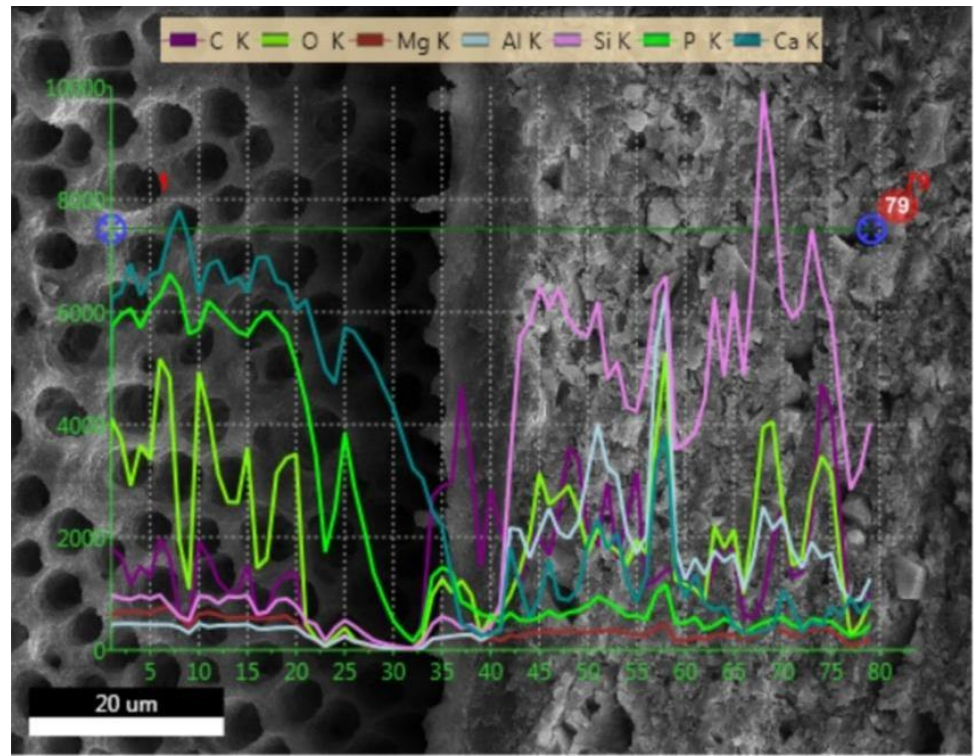

Figure 8. EDS line scan signals of individual elements present at dentin-resin interface obtained for Prime\&Bond One Select applied twice in $40 \mathrm{~s}$ (group 2A40).

\subsection{Shear Bond Strength}

Among all tested adhesives, the highest SBS results were obtained for Single Bond Universal, a universal adhesive (Table 4). The increase in number of applications up to three along with $60 \mathrm{~s}$ application time resulted in higher SBS for Single Bond Universal adhesive than the control group (from $16.34 \pm 4.62$ up to $31.40 \pm 2.83 \mathrm{MPa}$ ). 
Table 4. Shear bond strength (MPa) (mean values \pm standard deviation) of the tested adhesives.

\begin{tabular}{cccccc}
\hline \multirow{2}{*}{ Adhesive } & \multicolumn{5}{c}{ Method of Application } \\
\cline { 2 - 6 } & $\mathbf{1 A 2 0}$ (Control Group) & 2A20 & 3A20 & 2A40 & 3A60 \\
\hline Adper Easy One & $6.10 \pm 2.39 \mathrm{ab}^{\mathrm{a}}$ & $9.27 \pm 2.50 \mathrm{~cd}^{\mathrm{a}}$ & $9.14 \pm 2.95^{\mathrm{a}}$ & $15.19 \pm 2.15 \mathrm{ac}^{\mathrm{a}}$ & $16.86 \pm 2.29 \mathrm{bd}^{\mathrm{a}}$ \\
Xeno V & $2.24 \pm 1.02 \mathrm{ab}^{\mathrm{a}, \mathrm{b}}$ & $3.91 \pm 2.48^{\mathrm{a}, \mathrm{b}}$ & $7.00 \pm 2.11^{\mathrm{b}}$ & $7.67 \pm 2.15 \mathrm{a}^{\mathrm{b}}$ & $7.68 \pm 4.04 \mathrm{~b}^{\mathrm{b}}$ \\
Single Bond Universal & $16.34 \pm 4.62 \mathrm{ab}^{\mathrm{c}}$ & $19.40 \pm 4.45 \mathrm{c}^{\mathrm{b}, \mathrm{c}}$ & $20.7 \pm 4.17^{\mathrm{b}, \mathrm{c}}$ & $30.40 \pm 6.69 \mathrm{a} \mathrm{b}, \mathrm{c}$ & $31.40 \pm 2.83 \mathrm{bc} \mathrm{b}, \mathrm{c}$ \\
Prime\&Bond One Select & $4.04 \pm 1.40^{\mathrm{b}, \mathrm{c}}$ & $4.88 \pm 2.36^{\mathrm{c}}$ & $2.42 \pm 1.06^{\mathrm{ac}}$ & $4.65 \pm 3.25^{\mathrm{a}, \mathrm{c}}$ & $3.83 \pm 2.08^{\mathrm{a}, \mathrm{c}}$ \\
\hline
\end{tabular}

Within tested adhesives, means followed by the same lowercase letters in row and superscript letters in column indicate significant statistical differences.

When multi-mode adhesives were considered, Prime \& Bond One Select presented lower bond strength values in all study groups compared with Single Bond Universal (Figure 9). None of the modifications of application procedures contributed to a significant increase of SBS of Prime\&Bond One Select. In case of Single Bond Universal doubling or tripling the number of applications along with prolonged application time in groups $2 \mathrm{~A} 40$ and 3A60 resulted in a statistically significant increase in SBS.

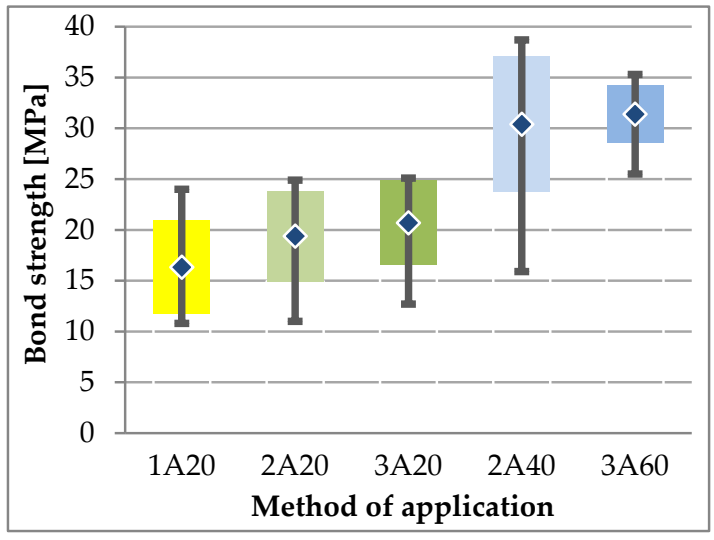

(a)

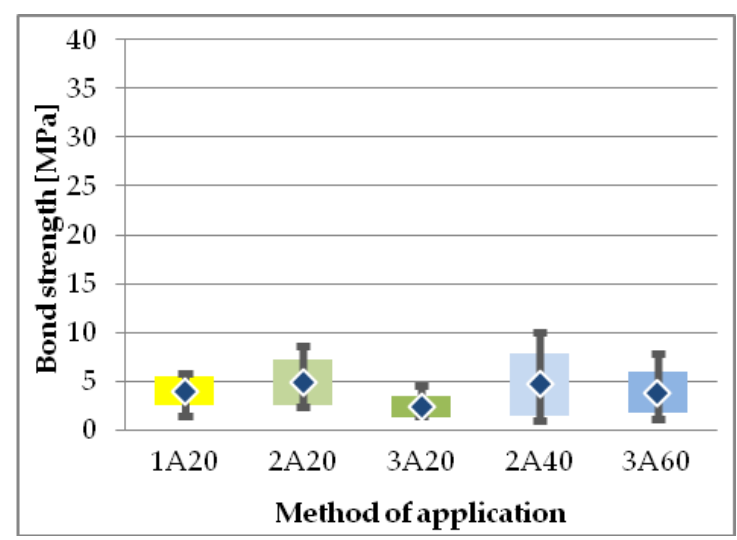

(b)

Figure 9. SBS results for multi-mode adhesives: (a) Single Bond Universal; (b) Prime \& Bond One Select.

The lowest values of SBS were observed for SE adhesive, Xeno V applied once (2.24 $\pm 1.0 \mathrm{MPa})$, however the bond strength significantly increased when application methods were modified. The highest mean SBS was observed in group 3A60 (7.68 $\pm 4.04 \mathrm{MPa})$ (Table 4, Figure 10b).

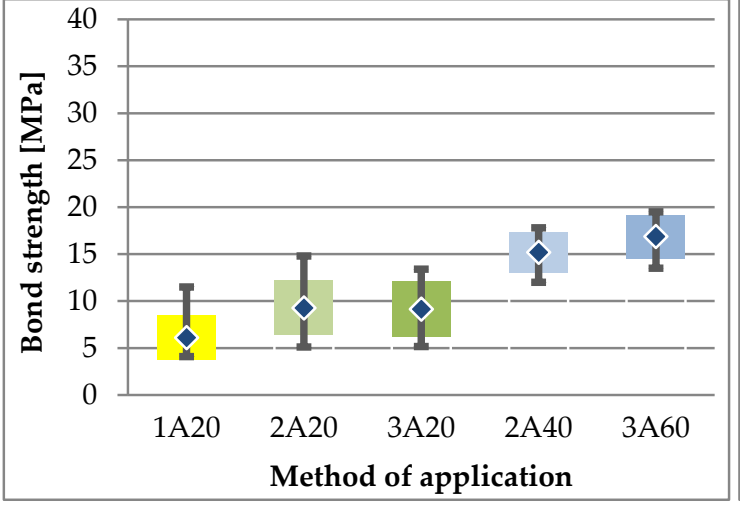

(a)

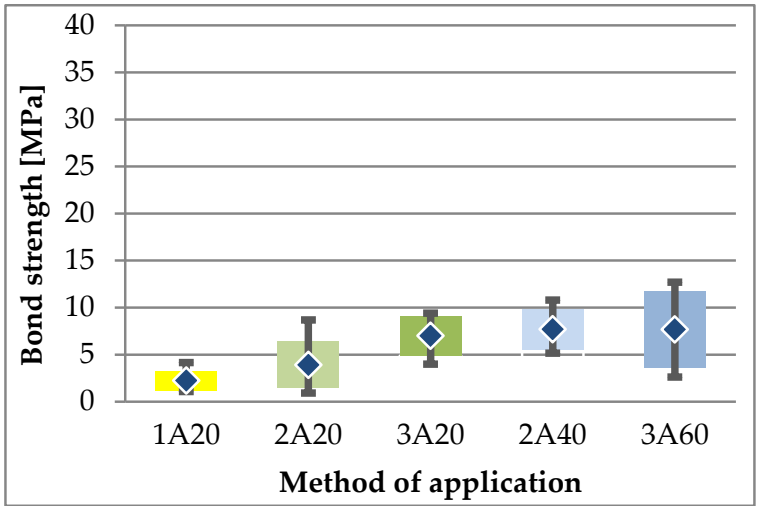

(b)

Figure 10. SBS results of self-etch adhesives: (a) Adper Easy One; (b) Xeno V. 
With regard to self-etch adhesives, SBS of Adper Easy One was higher than of Xeno V adhesive in all respective study groups. Bond strength values of both Adper Easy One and Xeno V increased in groups, which involved doubling or tripling application time: 2A40, 3A60 (Figure 10).

A significant interaction between factors (type of adhesive, modification of application procedure) was revealed using Kruskal-Wallis ANOVA. For most adhesives, except Prime \& Bond One Select, each modification contributed to an increase in SBS. However, Dunnett's post hoc test showed that the difference in bond strength was statistically significantly higher than the control only in 2A40 and 3A60 groups for Adper Easy One, Single Bond Universal and Xeno V (Figures 9 and 10).

For tested adhesives, there was no statically significant correlation between adhesive layer thickness and SBS: Adper Easy One $(p=0.909)$, Prime One Select $(p=0.568)$, Single Bond Universal $(p=0.698)$, and Xeno V $(p=0.841)$.

\section{Discussion}

A positive correlation between prolonged application time and higher resin-dentin bond strength values of simplified adhesives has been demonstrated [31,32]. This could be attributed to both higher penetration of monomers into decalcified dentin and higher water and solvent evaporation before light curing. The conversion degree and mechanical properties of the adhesive polymer are compromised if solvent content within the adhesive solution is high [33,34]. When water is present during the conversion from monomer to polymer, the formation of a cross-link polymer within the collagen fiber network is prevented [35-37]. Therefore, if the application procedure is prolonged, a thicker hybrid layer of higher conversion degree and better quality can be obtained [26,31,38].

Multiple application of SE and MM adhesives without light-curing each layer causes a minimal increase in the thickness of the adhesive layer (a physical factor), but it may have effects of chemical nature [8]. During the first application, the adhesive etches dentin, but is likely to be quickly buffered. Providing more acidic monomers during the next application may increase the ability of the adhesive to etch dentin. High-pressure or prolonged air-drying enhances solvent evaporation between successive applications of the adhesive. Therefore, the concentration of acidic monomers increases. This may contribute to a more thorough infiltration of the collagen fibers and more uniform polymerization of the adhesive [27]. Thus, without increasing the thickness, the adhesive layer of higher quality is obtained, which ensures a stronger bond between the adhesive and dentin [27].

The primary reasons for failure of composite restorations are secondary caries, marginal defects and restoration fracture [39]. Therefore, achieving a stable and durable bonding interface plays a significant role in terms of dental composite performance. There is abundant literature confirming the advantage of the etch-and-rinse over the self-etch approach when using enamel [40]. However, when dentin is regarded, the bonding strategy depends on the $\mathrm{pH}$ of the adhesive and its composition. Simplified adhesives are classified according to their acidity as strong $(\mathrm{pH} \leq 1)$, moderate $(1<\mathrm{pH}<2)$ or mild $(\mathrm{pH}=2)$ [40]. Ermis et al. [41] added the fourth group to this classification, the so-called ultra-mild adhesives $(\mathrm{pH} \geq 2.5)$. Low- $\mathrm{pH}$ adhesives present decreased dentin bond strength values when compared to mild ones [25]. The etching pattern they produce is similar to that of $37 \%$ phosphoric acid, but the dissolved calcium phosphates are not rinsed away and become embedded in hybrid layer. Since calcium phosphates are unstable in aqueous environments and considerably weaken the interfacial integrity, the use of strong SE adhesives is not recommended [3]. Self-etch or universal, mild adhesives are proven to achieve best dentin bond strength results when phosphoric acid etching is not involved [42]. When these adhesives are applied directly on unetched dentin, the tissue is partially demineralized. A substantial amount of hydroxyapatite crystals is left around the collagen fibrils. The micromechanical interaction takes place due to in situ polymerization of the monomers that infiltrate into the collagen network. Moreover, some of the universal adhesives interact chemically with hydroxyapatite. They contain functional monomers in their composition, such as MDP. These monomers interact chemically with calcium in the residual hydroxyapatite through ionic bonding, 
creating a non-soluble stable nano-layer [18,24]. It contributes to increasing mechanical strength and preventing the degradation over time of the bond interface.

When bonding to dentin is regarded, SE and universal adhesives still cannot compete with the excellent performance of conventional three step etch-and-rinse adhesives. In this study the efficacy of several methods to enhance their dentin bonding performance was evaluated, as well as their impact on the adhesive layer thickness. The methods included increasing the number of applications and extending the application time.

In the present study each modification of application procedure of Single Bond Universal contributed to an increase of SBS to dentin. The difference was not statistically significant in case of sole increased number of applications (2A20 and 3A20). However, in 2A40 and 3A60 groups, mean SBS results were significantly higher and almost doubled when compared to the control. It can be concluded that the chemical action of MDP monomer provided with subsequent applications in 2A20 and 3A20 groups could not fully develop in $20 \mathrm{~s}$. Only after the application procedure was multiplicated within the prolonged time, did it allow Single Bond Universal to achieve higher SBS values. The considerable improvement in bond durability is attributed to an additional chemical reaction between MDP and dentin [3]. According to the adhesion-decalcification (AD) concept, the intensity and stability of molecular adhesion of calcium salts of acidic monomers to HAp is inversely proportional to their solubility [43]. The MDP possesses relatively strong decalcification ability, which enables it to form stable monomer-calcium salts, manifested as 'nano-layering' [18]. A more water-stable interface is produced, therefore contributing to bond durability. The monomer consists of a methylmethacrylate group, which allows for light-polymerization, and a phosphoric-acid group, enabling ionic interaction with calcium of HAp. Both groups are separated by a 10-fold carbon chain, which is responsible for wetting, solubility, flexibility, and the hydrophobicity-hydrophilicity balance of the monomer [44]. All of the abovementioned features of MDP may also be the reason why Single Bond Universal had the highest mean SBS compared to all other adhesives used in this study. Especially in 2A40 and 3A60 groups, where additional portions of MDP were supplied and sufficient time was ensured, the results of SBS to dentin were the highest.

In the case of Prime \& Bond One Select, another universal adhesive used in this study, no study group obtained significantly higher results than the control. Mean SBS values were significantly lower than those of Single Bond Universal in each respective group. This was probably due to several mechanisms operating simultaneously. One factor is the adhesive layer thickness. Previous studies showed that increased adhesive layer thickness enhanced its elasticity [45]. Resin deformation suppressed polymerization, mastication or temperature-caused stress [46]. In this study it was measured that Prime \& Bond One Select obtained thinner adhesive layer than Single Bond Universal in each respective group. Prime \& Bond One Select applied in separately light-cured layers was shown to present both thicker adhesive layer and improved SBS [47]. Another factor contributing to the difference in bond strength between both universal adhesives is their acidity. The $\mathrm{pH}$ of Single Bond Universal is higher than of Prime\&Bond One Select (2.7 vs. 1.6, respectively), which makes them an ultra-mild and a moderate adhesive. As mentioned above, previous studies proved low-pH adhesives, such as Prime \& Bond One Select in this study, present lower bond strength than mild ones [25]. Another factor contributing to the higher SBS of Single Bond Universal in this study is the presence of inorganic nanofiller in its composition. Prime \& Bond One Select, on the other hand, is an unfilled adhesive. Studies confirmed, that adhesives created reinforced, thicker hybrid layers, due to increased viscosity, when filler was included in their composition [48]. "Inverse" functionalized phosphoric acid esters are components of Prime \& Bond One Select. As reported by the manufacturer, they are responsible for interacting chemically with dentin [49]. However, insufficient research is available to support the actual occurrence of this phenomenon. It should also be mentioned that, as described in the brochure provided by the manufacturer, all etching techniques: ER, SE and SEE can be utilized with Prime \& Bond One Select. The composition of this adhesive and of Xeno V (Table 1) is comparable, however, which makes Prime \& Bond One Select rather a SE product with broadened indications for 
use. The present study showed that Prime \& Bond One Select produced statistically higher SBS than Xeno $\mathrm{V}$ in the control group, whereas the modification of application mode resulted in comparable bonding performance of both adhesives.

In the case of Xeno V, multiplying the number of applications led to an increase of bond strength, but the differences were not statistically significant (2A20, 3A20). These results are in line with other studies, which concluded that multiple applications of all-in-one adhesives did not significantly affect their bond strength to dentin [50]. The main factor responsible for the increase of SBS to dentin of Xeno V in this study was prolonged application time. Mean bond strength results in 2A40 and 3A60 groups were significantly higher than control, but not statistically different from each other. The adhesive layer was also the thickest in these groups for Xeno V, although the differences were not statistically significant. Other studies confirm that prolonging the application time of all-in-one adhesives contributes to an increase of bond strength [26,31]. Thicker hybrid layer of higher conversion degree and better quality is obtained, which allows higher SBS results [26,31].

When Xeno V was compared to Adper Easy One, another SE adhesive used in this study, it obtained lower SBS results in all respective study groups. The analysis of the composition and the $\mathrm{pH}$ of both adhesives may provide an explanation. Adper Easy One contains nanofiller which, as explained above, contributes to enhancing the thickness and quality of the adhesive layer. In this study, Adper Easy One obtained almost double the results of Xeno V in terms of adhesive layer thickness $(13.31 \pm 0.43$ vs. $7.40 \pm 0.82 \mu \mathrm{m})$ in control group. In other groups the differences were not statistically significant. Also, Vitrebond ${ }^{\mathrm{TM}}$ Copolymer and MHP (methacrylohexyl phosphate) functional monomer are present in the composition of Adper Easy One. These chemical compounds are reported to bond chemically with hydroxyapatite by the formation of a complex with calcium ions [43], therefore enhancing SBS results. Moreover, Xeno V is a moderate adhesive in terms of acidity and Adper Easy One is a mild one. As mentioned above, mild adhesives generally show higher dentin bond strength than the ones of lower $\mathrm{pH}$ [25].

In the case of Adper Easy One, similarly to Xeno V, the main factor responsible for improving bond strength results was prolonged application time. SBS results in 2A20 and 3A20 groups were higher than the control, but the differences were not statistically significant. Multiplying the number of applications within a prolonged time resulted in the enhancement of bond strength (from $6.10 \pm 2.39 \mathrm{MPa}$ in control group to $16.86 \pm 2.29 \mathrm{MPa}$ in $3 \mathrm{~A} 60$ group). It can be concluded that when an additional amount of MHP was delivered with subsequent applications, the etching ability increased, more complete solvent evaporation was enabled, and an adhesive layer of better quality was obtained. Previous studies confirmed, that the quality of the adhesive layer is of paramount importance for dentin bond strength [26].

In terms of adhesive layer thickness results, Xeno $\mathrm{V}$ presented significantly higher, almost double mean thickness values after triple application in prolonged time of $60 \mathrm{~s}$ when compared to control. Most of the tested adhesives, Adper Easy One, Single Bond Universal, and Prime\&Bond One Select, obtained lower thickness results in 2A20 group than in control or other study groups. However, for Prime \& Bond One Select, the comparison of all the study groups with the control in terms of adhesive layer thickness proved that there was no statistically significant difference between them. The present study reported the great variability of the adhesive layer thickness measurements, that may result from a low number of specimens and few measurement points usually used in SEM observations [30]. Also, faulty positioning of the samples or undefined reference points could influence the measurements of adhesive layer thickness [51].

The present study showed that the correlation between dentin shear bond strength and adhesive layer thickness produced by tested all-in-one adhesives was statistically insignificant. Previous study reported similar findings on the lack of positive correlation between these parameters [52,53], depicting that it is the quality of the adhesive layer that might play a key role in dentin bond strength [51]. The increase in SBS of self-etch and universal adhesives observed in the present study could be related to an improvement of the resin-dentin interface quality, or the quality of the adhesive layer rather than 
to an increase in its thickness. This is in line with the findings of previous studies, which showed that some alterations of application procedures of all-in-one adhesives improved the quality of hybrid and/or adhesive layer and consequently led to an increase of SBS [25,27,50,54]. For all tested all-in-one adhesives, except for Prime\&Bond One Select, increased number of applications along with extended application time (groups 2A40 and 3A60) resulted in significant increase in SBS when compared to the controls.

The limitations of this in vitro study should be taken into consideration. Bond strength tests are generally a valuable tool aiming to rank dental adhesives according to their bond strength performance. However, they do not examine crucial factors influencing bond strength, which take place in clinical situation, such as $\mathrm{pH}$, temperature changes, moisture or masticatory stress [55]. Some authors regard bond strength tests to be invalid in order to conclude the clinical results of dental adhesives [56]. Other studies proved a relationship between bond strength values and clinical performance of these adhesives [16]. Therefore, as long as the validity of this study to predict the behavior of tested adhesives in the oral cavity is questionable, it can provide valuable data to identify substrate variables and establish the most effective application protocol for each adhesive tested. This information is relevant especially in clinically demanding situations where maximum bond strength is required, e.g., fiber post cementation, direct pulp capping, or class V cavity.

Considering the abovementioned results, the first part of the null hypothesis can be partially rejected; it is supported in case of Prime \& Bond One Select and rejected in the case of Single Bond Universal, Xeno V, and Adper Easy One. Increasing the number of applications to two or three and extending the application time (40-60 s) significantly improved bond strength of the latter adhesives to dentin. Prime \& Bond One Select showed no enhancement of bond strength to dentin in study groups. The second part of the null hypothesis, considering adhesive layer thickness after modified application, is rejected. The tested adhesives did not present increased thickness of the adhesive layer in the study groups. Furthermore, the third part of the null hypothesis is refuted. Improved bond strength of tested adhesives did not correspond with an increase of adhesive layer thickness.

\section{Conclusions}

Within the limitations of this study, modifying the application protocol of self-etch and universal adhesives by increasing the number of applications (two or three) and extending the application time (40-60 s) can be recommended to improve their performance. No correlation between adhesive layer thickness and bond strength of the tested adhesives was determined. The exact protocol of application of each product should be determined to ensure maximum performance due to the diverse compositions of simplified all-in-one adhesives.

Author Contributions: Conceptualization, A.Z.-D. and J.S.; methodology, B.L., M.L.-S. and I.P.; software, A.S.-W. and I.P.; validation, B.L., J.S. and M.L.-S.; formal analysis, A.Z.-D. and B.L.; investigation, A.Z.-D., I.P. and B.L.; resources, A.Z.-D. and J.S.; data curation, A.Z.-D. and B.L.; writing-original draft preparation, A.Z.-D. and B.L; writing-review and editing, B.L. and M.L.-S.; visualization, B.L.; supervision, B.L.; project administration, A.Z.-D., J.S. and B.L.; funding acquisition, J.S. All authors have read and agreed to the published version of the manuscript.

Funding: This research was funded by the Medical University of Lodz and the Ministry of Science and Higher Education, Poland, grant number 502-03/2-148-04/502-24-071.

Conflicts of Interest: The authors declare no conflict of interest. The funders had no role in the design of the study; in the collection, analyses, or interpretation of data; in the writing of the manuscript, or in the decision to publish the results.

\section{References}

1. Buonocore, M.G. A simple method of increasing the adhesion of acrylic filling materials to enamel surfaces. J. Dent. Res. 1955, 34, 849-853. [CrossRef]

2. Lapinska, B.; Klimek, L.; Sokolowski, J.; Lukomska-Szymanska, M. Dentine Surface Morphology after Chlorhexidine Application-SEM Study. Polymers (Basel) 2018, 10, 905. [CrossRef] 
3. Van Meerbeek, B.; Yoshihara, K.; Yoshida, Y.; Mine, A.; De Munck, J.; Van Landuyt, K.L. State of the art of self-etch adhesives. Dent. Mater. 2011, 27, 17-28. [CrossRef]

4. Sezinando, A. Looking for the ideal adhesive-A review. Rev. Port. Estomatol. Med. Dent. Cir. Maxilofac. 2014, 55, 194-206. [CrossRef]

5. Pashley, D.H.; Tay, F.R.; Breschi, L.; Tjäderhane, L.; Carvalho, R.M.; Carrilho, M.; Tezvergil-Mutluay, A. State of the art etch-and-rinse adhesives. Dent. Mater. 2011, 27, 1-16. [CrossRef]

6. Sofan, E.; Sofan, A.; Palaia, G.; Tenore, G.; Romeo, U.; Migliau, G. Classification review of dental adhesive systems: From the IV generation to the universal type. Ann. Stomatol. (Roma). 2017, 8, 1.

7. Lukomska-Szymanska, M.; Sokolowski, J.; Lapinska, B. Current views on adhesive bonding systems. J. Stomatol. 2017, 70, 384-393.

8. Zecin-Deren, A.; Sokolowski, J.; Lapinska, B. Contemporary views on multiple application of self-etch adhesives-Review of literature. J. Stomatol. 2015, 68, 736-751.

9. De Goes, M.F.; Giannini, M.; Foxton, R.M.; Nikaido, T.; Tagami, J. Microtensile bond strength between crown and root dentin and two adhesive systems. J. Prosthet. Dent. 2007, 97, 223-228. [CrossRef]

10. Lo Giudice, G.; Cutroneo, G.; Centofanti, A.; Artemisia, A.; Bramanti, E.; Militi, A.; Rizzo, G.; Favaloro, A.; Irrera, A.; Lo Giudice, R.; et al. Dentin morphology of root canal surface: A quantitative evaluation based on a scanning electronic microscopy study. BioMed Res. Int. 2015, 2015, 164065. [CrossRef]

11. Chieruzzi, M.; Rallini, M.; Pagano, S.; Eramo, S.; D’Errico, P.; Torre, L.; Kenny, J.M. Mechanical effect of static loading on endodontically treated teeth restored with fiber-reinforced posts. J. Biomed. Mater. Res. Part B Appl. Biomater. 2014, 102, 384-394. [CrossRef]

12. Sokolowski, G.; Szynkowska, M.I.; Sokolowska, D.; Lapinska, B.; Domarecka, M.; Sokolowski, J. Bonding of self-adhesive cements to dentin with self-etching adhesive systems. Przem. Chem. 2014, 93, 1607-1611.

13. Caldas, I.P.; Alves, G.G.; Barbosa, I.B.; Scelza, P.; de Noronha, F.; Scelza, M.Z. In vitro cytotoxicity of dental adhesives: A systematic review. Dent. Mater. 2019, 35, 195-205. [CrossRef]

14. Krawczyk-Stuss, M.; Ostrowska, A.; Lapinska, B.; Nowak, J.; Boltacz-Rzepkowska, E. Evaluation of Shear Bond Strength of the Composite to Biodentine with Different Adhesive Systems. Dent. Med. Probl. 2015, 52, 434-439. [CrossRef]

15. Cervino, G.; Fiorillo, L.; Spagnuolo, G.; Bramanti, E.; Laino, L.; Lauritano, F.; Cicciù, M. Interface between MTA and dental bonding agents: Scanning electron microscope evaluation. J. Int. Soc. Prev. Community Dent. 2017, 7, 64-68.

16. Peumans, M.; Kanumilli, P.; Munck De, J.; Landuyt Van, K.; Lambrechts, P.; Meerbeek Van, B. Clinical effectiveness of contemporary adhesives: A systematic review of current clinical trials. J. Esthet. Restor. Dent. 2010, 22, 73-74.

17. Alex, G. Universal adhesives: The next evolution in adhesive dentistry? Compend. Contin. Educ. Dent. 2015, $36,15-26$.

18. Yoshida, Y.; Yoshihara, K.; Nagaoka, N.; Hayakawa, S.; Torii, Y.; Ogawa, T.; Osaka, A.; Meerbeek, B. Van Self-assembled nano-layering at the adhesive interface. J. Dent. Res. 2012, 91, 376-381. [CrossRef]

19. Lukomska-Szymanska, M.; Sokolowski, J.; Lapinska, B. Degradation of a hybrid layer-Review of literature. J. Stomatol. 2017, 70, 88-94.

20. Papadogiannis, D.; Dimitriadi, M.; Zafiropoulou, M.; Gaintantzopoulou, M.D.; Eliades, G. Universal adhesives: Setting characteristics and reactivity with dentin. Materials (Basel) 2019, 12, 1720. [CrossRef]

21. Lapinska, B.; Konieczka, M.; Zarzycka, B.; Sokolowski, K.; Grzegorczyk, J.; Lukomska-Szymanska, M. Flow Cytometry Analysis of Antibacterial Effects of Universal Dentin Bonding Agents on Streptococcus mutans. Molecules 2019, 24, 532. [CrossRef]

22. Pagano, S.; Lombardo, G.; Balloni, S.; Bodo, M.; Cianetti, S.; Barbati, A.; Montaseri, A.; Marinucci, L. Cytotoxicity of universal dental adhesive systems: Assessment in vitro assays on human gingival fibroblasts. Toxicol. In Vitro 2019, 60, 252-260. [CrossRef]

23. Oz, F.D.; Ergin, E.; Canatan, S. Twenty-four-month clinical performance of different universal adhesives in etch-and-rinse, selective etching and self-etch application modes in NCCL-A randomized controlled clinical trial. J. Appl. Oral Sci. 2019, 27, e20180358. [CrossRef]

24. Hanabusa, M.; Mine, A.; Kuboki, T.; Momoi, Y.; Van Ende, A.; Van Meerbeek, B.; De Munck, J. Bonding effectiveness of a new "multi-mode" adhesive to enamel and dentine. J. Dent. 2012, 40, 475-484. [CrossRef] 
25. Belli, R.; Dalmagro, L.; Coutinho, J.; Sartori, N.; Peruchi, L.D.; Guimarães, J.C.; Vieira, L.C.; Baratieri, L.N.; Monteiro, S. Effect of multiple coats of ultra-mild all-in-one adhesives on bond strength to dentin covered with two different smear layer thicknesses. J. Adhes. Dent. 2011, 13, 507-516.

26. De Carvalho Cardoso, P.; Loguercio, A.D.; Vieira, L.C.C.; Baratieri, L.N.B.; Reis, A. Effect of prolonged application times on resin-dentin bond strengths. J. Adhes. Dent. 2005, 7, 143-149.

27. Chowdhury, A.; Mohammad, A.F.; Saikaew, P.; Alam, A.; Sun, J.; Carvalho, R.M.; Sano, H. Effects of double application of contemporary self-etch adhesives on their bonding performance to dentin with clinically relevant smear layers. J. Adhes. Dent. 2019, 21, 59-66.

28. Paul, J.; Chakravarthy, Y.; Kumar, S.; Rahna, R. Comparative evaluation of the bonding efficacy of sixth, seventh and eighth generation bonding agents: An in vitro study. Int. Res. J. Pharm. 2013, 2, $143-147$. [CrossRef]

29. Lukomska-Szymanska, M.; Konieczka, M.; Zarzycka, B.; Lapinska, B.; Grzegorczyk, J.; Sokolowski, J. Antibacterial activity of commercial dentine bonding systems against E. faecalis-flow cytometry study. Materials (Basel) 2017, 10, 481. [CrossRef]

30. De Cerqueria Luz, M.A.A.; Arana-Chavez, V.F.; Netto, N.G. Scanning electron microscopy examination of 3 different adhesive systems. Quintessence Int. 2005, 36, 687-694.

31. Reis, A.; de Carvalho Cardoso, P.; Vieira, L.C.C.; Baratieri, L.N.; Grande, R.H.M.; Loguercio, A.D. Effect of prolonged application times on the durability of resin-dentin bonds. Dent. Mater. 2008, 24, 639-644. [CrossRef] [PubMed]

32. Toledano, M.; Proença, J.P.; Erhardt, M.C.G.; Osorio, E.; Aguilera, F.S.; Osorio, R.; Tay, F.R. Increases in dentin-bond strength if doubling application time of an acetone-containing one-step adhesive. Oper. Dent. 2007, 32, 133-137. [CrossRef] [PubMed]

33. Reis, A.; Grandi, V.; Carlotto, L.; Bortoli, G.; Patzlaff, R.; Rodrigues Accorinte, M.D.L.; Dourado Loguercio, A. Effect of smear layer thickness and acidity of self-etching solutions on early and long-term bond strength to dentin. J. Dent. 2005, 33, 549-559. [CrossRef] [PubMed]

34. Ye, Q.; Spencer, P.; Wang, Y.; Misra, A. Relationship of solvent to the photopolymerization process, properties, structure in model dentin adhesives. J. Biomed. Mater. Res. Part A 2007, 80, 342-350. [CrossRef] [PubMed]

35. Jacobsen, T.; Söderholm, K.-J.J. Some effects of water on dentin bonding. Dent. Mater. 1995, 11, $132-136$. [CrossRef]

36. Paul, S.J.; Leach, M.; Rueggeberg, F.A.; Pashley, D.H. Effect of water content on the physical properties of model dentine primer and bonding resins. J. Dent. 1999, 27, 209-214. [CrossRef]

37. Sokolowski, G.; Szczesio, A.; Bociong, K.; Kaluzinska, K.; Lapinska, B.; Sokolowski, J.; Domarecka, M.; Lukomska-Szymanska, M. Dental resin cements-The influence of water sorption on contraction stress changes and hydroscopic expansion. Materials (Basel) 2018, 11, 973. [CrossRef]

38. Erhardt, M.C.; Osorio, R.; Pisani-Proenca, J.; Aguilera, F.S.; Osorio, E.; Breschi, L.; Toledano, M. Effect of Double Layering and Prolonged Application Time on MTBS of Water/Ethanol-based Self-etch Adhesives to Dentin. Oper. Dent. 2009, 34, 571-577. [CrossRef]

39. Brunthaler, A.; König, F.; Lucas, T.; Sperr, W.; Schedle, A. Longevity of direct resin composite restorations in posterior teeth. Clin. Oral Investig. 2003, 7, 63-70. [CrossRef]

40. Van Meerbeek, B.; De Munck, J.; Yoshida, Y.; Inoue, S.; Vargas, M.; Vijay, P.; Van Landuyt, K.; Lambrechts, P.; Vanherle, G. Buonocore memorial lecture. Adhesion to enamel and dentin: Current status and future challenges. Oper. Dent. Wash. 2003, 28, 215-235.

41. Ermis, R.B.; De Munck, J.; Cardoso, M.V.; Coutinho, E.; Van Landuyt, K.L.; Poitevin, A.; Lambrechts, P.; Van Meerbeek, B. Bond strength of self-etch adhesives to dentin prepared with three different diamond burs. Dent. Mater. 2008, 24, 978-985. [CrossRef] [PubMed]

42. Cuevas-Suárez, C.E.; de Oliveira da Rosa, W.L.; Lund, R.G.; da Silva, A.F.; Piva, E. Bonding Performance of Universal Adhesives: An Updated Systematic Review and Meta-Analysis. J. Adhes. Dent. 2019, 21, 7-26. [PubMed]

43. Fujita, K.; Nikaido, T.; Arita, A.; Hirayama, S.; Nishiyama, N. Demineralization capacity of commercial 10-methacryloyloxydecyl dihydrogen phosphate-based all-in-one adhesive. Dent. Mater. 2018, 34, 1555-1565. [CrossRef] 
44. Van Landuyt, K.L.; Snauwaert, J.; De Munck, J.; Peumans, M.; Yoshida, Y.; Poitevin, A.; Coutinho, E.; Suzuki, K.; Lambrechts, P.; Van Meerbeek, B. Systematic review of the chemical composition of contemporary dental adhesives. Biomaterials 2007, 28, 3757-3785. [CrossRef] [PubMed]

45. Pashley, E.L.; Agee, K.A.; Pashley, D.H.; Tay, F.R. Effects of one versus two applications of an unfilled, all-in-one adhesive on dentine bonding. J. Dent. 2002, 30, 83-90. [CrossRef]

46. Ahmed, M.H.; De Munck, J.; Van Landuyt, K.; Peumans, M.; Van Meerbeek, B.; Yoshihara, K. Do universal adhesives benefit from an extra bonding layer? J. Adhes. Dent. 2019, 21, 117-132. [PubMed]

47. Zecin-Deren, A.; Sokolowski, J.; Szczesio-Wlodarczyk, A.; Piwonski, I.; Lukomska-Szymanska, M.; Lapinska, B. Multi-Layer Application of Self-Etch and Universal Adhesives and the Effect on Dentin Bond Strength. Molecules 2019, 24, 345. [CrossRef] [PubMed]

48. Kasraei, S.H.; Atai, M.; Khamverdi, Z.; Nejad, S.K. Effect of Nanofiller Addition to an Experimental Dentin Adhesive on Microtensile Bond Strength to Human Dentin. J. Dent. Tehran Univ. Med. Sci. 2009, 6, 91-96.

49. Lattaa, M.A. Shear bond strength and physicochemical interactions of XP Bond. J. Adhes. Dent. 2007, 9 (Suppl. 2), 245-248.

50. Albuquerque, M.; Pegoraro, M.; Mattei, G.; Reis, A.; Loguercio, A.D. Effect of double-application or the application of a hydrophobic layer for improved efficacy of one-step self-etch systems in enamel and dentin. Oper. Dent. 2008, 33, 564-570. [CrossRef]

51. D'Arcangeloa, C.; Vanini, L.; Prosperi, G.D.; Di Bussolo, G.; De Angelis, F.; D'Amario, M.; Caputi, S. The clinical Influence of Adhesive Thickness on the Microtensile Bond Strength of Three Adhesive Systems. J. Adhes. Dent. Conserv. Dent. 2009, 11, 109-115.

52. Rahal, V.; de Oliveira, F.G.; Briso, A.L.; dos Santos, P.H.; Sundefeld, M.L.; Sundfeld, R.H. Correlation between hybrid layer thickness, resin tag length and microtensile bond strength of a self-etching adhesive system. Acta Odontol. Latinoam. 2012, 25, 231-237.

53. Lodovici, E.; Reis, A.; Geraldeli, S.; Ferracane, J.L.; Ballester, R.Y.; Filho, L.E.R. Does Adhesive Thickness Affect Resin-dentin Bond Strength after Thermal/Load Cycling? Oper. Dent. 2009, 34, 58-64. [CrossRef]

54. Chasqueira, A.F.; Arantes-Oliveira, S.; Portugal, J. Effect of changes to the manufacturer application techniques on the shear bond strength of simplified dental adhesives. J. Appl. Biomater. Funct. Mater. 2013, 11, 117-121. [CrossRef]

55. Da Rosa, W.L.D.O.; Piva, E.; Da Silva, A.F. Bond strength of universal adhesives: A systematic review and meta-analysis. J. Dent. 2015, 43, 765-776. [CrossRef]

56. Braga, R.R.; Meira, J.B.C.; Boaro, L.C.C.; Xavier, T.A. Adhesion to tooth structure: A critical review of "macro" test methods. Dent. Mater. 2010, 26, e38-e49. [CrossRef] 